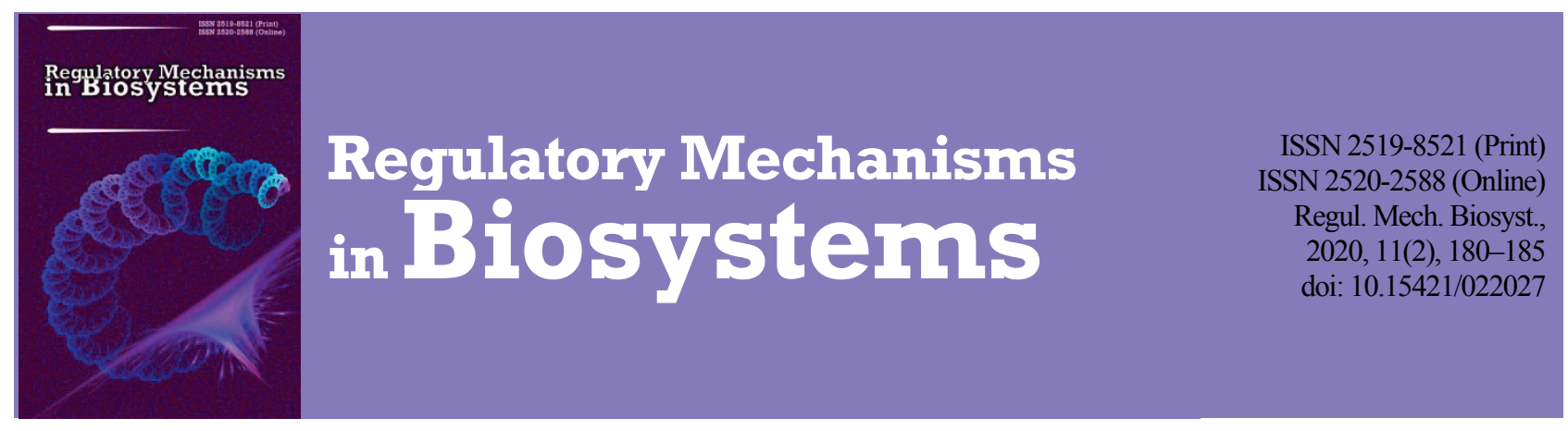

\title{
Long-term effects of acute cadmium exposure on testis immune privilege
}

\author{
B. Deng*, O. V. Pakhomov**, G. A. Bozhok** \\ *Henan University of Science and Technology, Luoyang, China \\ **Institute for Problems of Cryobiology and Cryomedicine of the National Academy of Sciences of Ukraine, Kharkiv, Ukraine
}

Article info

Received 09.03.2020

Received in revised form 01.04 .2020

Accepted 02.04.2020

Henan University of Science

and Technology,

Kaiyuan ave., 263

Luolong Qu, Luoyang Shi.

Henan Sheng, 471023,

China.

Tel: $+86-379-642-318-79$

E-mail:fao@haust.edu.cn

Institute for Problems

of Cryobiology and

Cryomedicine of the

National Academy of

Sciences of Ukraine,

Pereyaslavskaya st., 23,

Kharkiv, 61016, Ukraine.

Tel: + 38-057-373-4l-43

E-mail:

cryo@online.kharkov.ua

\begin{abstract}
Deng, B., Pakhomov, O. V., \& Bozhok, G. A. (2020). Long-term effects of acute cadmium exposure on testis immune privilege.
\end{abstract} Regulatory Mechanisms in Biosystems, 11(2), 180-185. doi:10.15421/022027

Cadmium $(\mathrm{Cd})$ is a widespread and non-biodegradable pollutant of great concern to human health. This element can affect cellular signal transduction and cell-to-cell interaction in the testis. Immune tolerance towards auto- and alloantigens is an important component of testis immunity. It is involved in spermatogenesis and hormone secretion. Plus, the immune tolerance may help to reveal the changes in testis immunity over a long period after $\mathrm{Cd}$ exposure. The current research was aimed at investigating the long-term effects of acute $\mathrm{Cd}$ exposure on testis immunity by means of elicitation of testicular immune cell composition shift induced by $\mathrm{Cd}$. Cadmium chloride was intraperitoneally injected at $3 \mathrm{mg} \mathrm{Cd} / \mathrm{kg}$ to mice. After that testis interstitial cells were stained with surface markers for leukocyte and lymphocyte subpopulations (CD45, CD11b, CD3, CD4, CD8, CD25) and analyzed cytofluorimetrically by week 4, 6, 8 and 12 after $\mathrm{Cd}$ administration (Cd group). To identify the delayed effects of cadmium on immune tolerance two groups of animals were subjected to intratesticular allotransplantation of neonatal testis (groups ITT and $\mathrm{Cd}^{+}$ITT). One of the groups was administered with $\mathrm{Cd}$ four weeks before the transplantation (Cd $\mathrm{Cd}^{+} \mathrm{TT}$ group). I group served as a control that did not undergo any transplantation or $\mathrm{Cd}$ injection. For a better demonstration of the phenomenon of immunological tolerance of the testicles, an additional group (UKT group) was used which got grafts under the kidney capsule (non-immune privileged site).Investigation of the cell population showed that $\mathrm{CD} 45+, \mathrm{CD} 11 \mathrm{~b}+, \mathrm{CD} 4+, \mathrm{CD} 8+$ cells were permanently present in testicular interstitial tissue in I group. Intratesticular testis transplantation increased the proportion of $\mathrm{CD} 11 \mathrm{~b}+$ but did not have such a pronounced effect on CD8+ cells in ITT group. Moreover, the transplantation elevated CD4+ CD25+ cells known for their immunosuppressive property and promoted graft development by week 2 (histological data). Cd injection resulted in severe inflammation that quenched by week $4\left(\mathrm{Cd}_{\text {and }} \mathrm{Cd}^{+}\right.$ ITT groups). This time point was chosen for transplantation in $\mathrm{Cd}^{+}$ITT group. Such Cd pretreatment led to a high $\mathrm{CD} 8+$ cell proportion and to the delayed appearance of CD4+ $\mathrm{CD} 25+$ cells by week 2 (Cd ITTgroup). The finding is consistent with the impairment of graft development in $\mathrm{Cd}^{+}$ITTgroup pretreated with $\mathrm{Cd}$. Observation suggest that $\mathrm{Cd}$ pretreatment was associated with disproportion of interstitial immune cell populations which resulted in the impairment of immunoprotective function of the testis. The impairment of testis immunity showed itself only after several weeks of $\mathrm{Cd}$ administration, and only when the recipient testis immunity was provoked by alloantigens of donor testes.

Keywords: cadmium; heavy metal toxicity; immune privilege; male fertility; testis transplantation; T regulatory cells.

\section{Introduction}

Cadmium $(\mathrm{Cd})$ is a ubiquitous and non-biodegradable pollutant representing a great concern to human health. High Cd exposure has been reported among workers in the construction and manufacturing industries such as mining for metals or in the manufacture of pigments and batteries (Samuel-Nakamura et al., 2019). In the general population, the main sources of exposure are food, cigarette smoking, inhalation of ambient air, drinking water, contaminated soil or dust (Rinaldi et al., 2017). It may also cause a serious disease known as itai-itai, which is the most severe stage of chronic Cd poisoning (Aoshima, 2017). The toxicant may induce irreversible injuries in multiple organs such as liver, kidney, brain, lungs and testes (Yang \& Shu, 2015; Hu et al., 2017; Halder et al., 2019; Salama et al., 2019).

Testes are especially vulnerable to Cd exposure. At the tissue level it may result in endothelial damage, hemorrhage, edema and testis calcification (Marettová et al., 2010; Mouro et al., 2020). At the molecular level $\mathrm{Cd}$ is known for its disruption of redox balance and specific disintegration of blood-testis barrier (BTB) and Sertoli cell-spermatid adhesion (Chen et al., 2018). It decreases occludin, claudin-11, nectin-2 expressions that are required for the normal tight and gap junction formation and are responsible for maintaining the BTB (Zhang \& Lui, 2014;
Ramos-Treviño et al., 2017). The Cd-induced disruption of testicular function is mediated by its effects on the occludin/ZO-1/focal adhesion kinase complex at the BTB, causing redistribution of proteins at the Sertoli-Sertoli cell interface. The damaging effects of $\mathrm{Cd}$ to testicular function are also mediated by mitogen-activated protein kinases downstream, which in turn perturbs the actin bundling and accelerates the actin-branching activity, causing disruption of the Sertoli cell tight junction and perturbing spermatid adhesion at the apical ectoplasmic specialization (a testis-specific anchoring junction type) that leads to premature release of germ cells from the testis (Cheng et al., 2011; RamosTrevino et al., 2018).

The immune system of the organ, its spermatogenesis and steroidogenesis are interlinked by a network of complex interaction which is thoroughly reviewed in (Chen et al., 2018; Mossadegh-Keller \& Siewe$\mathrm{ke}, 2018)$. The testis is known for its immune privilege status. This evolutionary adaptation protects spermatogenesis from the auto-immune system. Testicular immune privilege is a complex phenomenon which is a result of the combined contribution of cellular and humoral components of testes rather than a single cell type or humoral factor acting alone. Few attempts were undertaken to assess the change in the testicular immune component and immune privilege status after $\mathrm{Cd}$ pretreatment. It has been shown that $\mathrm{Cd}$ injection resulted in an increase in the 
level of pro-inflammatory cytokine (TNF- $\alpha$ ) and in the alteration of macrophage shape and composition compromising immune privilege (Chakraborty et al., 2014). However, the abovementioned changes were investigated immediately after $\mathrm{Cd}$ exposure.

Hence, it is interesting to investigate the consequences of Cd exposure on a long-time scale after $\mathrm{Cd}$ administration and the profile of some testicular immune cells playing a role in the testis immunity such as macrophages, dendritic cells, T lymphocytes. Intratesticular testis transplantation may provide a model for the investigation of testicular defects (Schlatt et al., 2003; Hutka et al., 2017). One consequence of the immune privilege is the ability to prolong the survival of intratesticular transplanted graft. Thus, this feature can potentially be used for the assessment of the long-term changes in testicular immune privilege status after $\mathrm{Cd}$ exposure when Sertoli and germinal cell contact were compromised long before the transplantation. Additionally, the investigation of testicular tissue under transplantation itself may contribute to the development of new approaches for breeding laboratory animals (Shaw \& Trounson, 2002; Schlatt et al., 2003) and human reproductive technology (McCracken \& Nahata, 2017).

Therefore, this study aims to understand the inter-relation between testicular immune cells such as macrophage, granulocytes and some types of lymphocytes in maintaining normal immune status in the testis and the mechanism by which Cd disrupts this harmony at the cellular level. The results may provide an insight into the long-term impact of $\mathrm{Cd}$ on an organism in order to develop novel treatment approaches for acute and chronic $\mathrm{Cd}$ intoxication and for male fertility preservation or restoration.

\section{Materials and methods}

Male CBA mice were kept in the animal house of the Institute for Problems of Cryobiology and Cryomedicine of the National Academy of Sciences of Ukraine (Kharkiv, Ukraine). The animals were housed six per cage, with 12 hour light-dark cycle. The experimental protocol was followed according to the Guide for Care and Use of Laboratory Animals, which was approved by the Committee for Bioethics in Animal Experimentation of the Institute for Problems of Cryobiology and Cryomedicine of the National Academy of Sciences of Ukraine and is subject to the European Convention for the Protection of Vertebrate Animals used for Experimental and Other Scientific Purposes.

The research scheme is presented in the diagram (Fig. 1). The animals were divided into five groups. Cd group was given a single intraperitoneal dose of $\mathrm{CdCl}_{2}, 3 \mathrm{mg} / \mathrm{kg}$ of body weight. ITT group was intratesticularly transplanted with neonatal murine testes, 4 testes per recipient. $\mathrm{Cd}^{+}$ITT group obtained intratesticular neonatal testis transplantation after four weeks of $\mathrm{Cd}$ pretreatment. Additionally, one group was transplanted with neonatal murine testis under the kidney capsule (UKT group). This group helped to elucidate the phenomenon of immune tolerance. Plus, an intact group (I group) was used that did not get any transplantation or Cd injection.

The age of donors did not exceed 24 hours. These donor mice were sacrificed and testes were taken through the incision of abdominal cavity. Then they were placed into the cold $\left(+4^{\circ} \mathrm{C}\right)$ PBS supplemented with $100 \mathrm{IU} / \mathrm{mL}$ penicillin (Arterium Corporation, Ukraine) and $100 \mu \mathrm{g} / \mathrm{mL}$ streptomycin (Arterium Corporation, Ukraine). These isolated organs were used as grafts for transplantation. The time span between isolation and transplantation came to about 10-20 minutes.

All surgical procedures were carried out under ketamine-xylazine anesthesia (ketamine $-80 \mathrm{mg} / \mathrm{kg} \mathrm{BW}$; xylazine $-20 \mathrm{mg} / \mathrm{kg} \mathrm{BW}$ ). In case of intratesticular allotransplantation, $5-7 \mathrm{~mm}$ ventral midline incision of abdominal cavity was made. The left testis was pulled out from the abdominal cavity. Then the tunica albuginea was pierced and the graft (neonatal testes) was placed into the testicular parenchyma of adult mice through the puncture. After that the left testis with graft was placed back into the abdominal cavity. In case of under the kidney capsule allotransplantation, the kidney was gently externalized off the abdominal cavity. Then, a small incision in the capsule was made with the spring scissors. The kidney was kept moist with warm sterile saline (PBS supplemented with $100 \mathrm{IU} / \mathrm{mL}$ penicillin and $100 \mu \mathrm{g} / \mathrm{mL}$ strep- tomycin). Then a shallow subcapsular pocket was made with a blunt probe and the graft was placed into the pocket with forceps. Finally, the muscles and skin were layer-by-layer sutured.

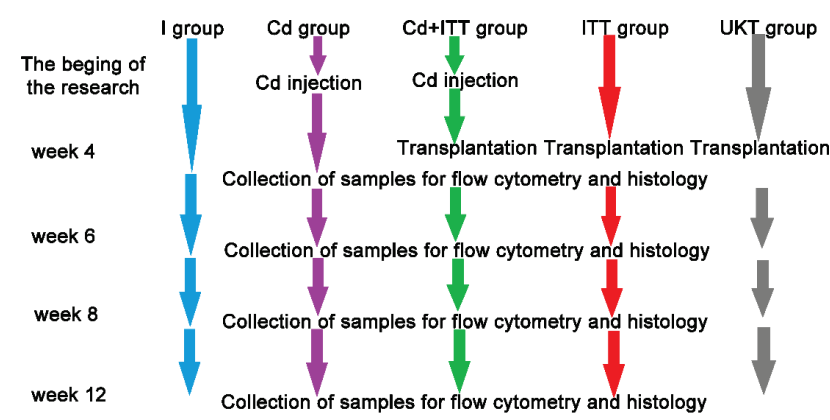

Fig. 1. The scheme of the research

The $\mathrm{Cd}$ pretreated animals ( $\mathrm{Cd}$ and $\mathrm{Cd}^{+}$ITT groups) were slaughtered by weeks $4,6,8$ and 12 after $\mathrm{Cd}$ administration. In case of $\mathrm{Cd}^{+}$ITT group these terms corresponded to week $0,2,4$ and 8 after intratesticular transplantation. Groups that were given transplantations only (ITT and UKT) were also slaughtered by weeks 2, 4 and 8 after transplantation. Their organs with grafts were examined histologically. Interstitial cell suspension obtained from testes with intratesticular grafts underwent flow cytometric analysis.

The testes were decapsulated, trimmed of blood vessels and placed in $15 \mathrm{~mL}$ centrifuge tubes with $4 \mathrm{~mL}$ DMEM (PAA, Austria) per testis with $0.2 \mathrm{mg} / \mathrm{mL}$ collagenase (type I) (Sigma-Aldrich, USA) and $0.1 \mathrm{mg} / \mathrm{mL}$ DNase I (Sigma-Aldrich, USA) for $10 \mathrm{~min}$ in a thermostatted shaking water bath $\left(90\right.$ cycles $/ \mathrm{min}$ at $\left.34^{\circ} \mathrm{C}\right) .10 \mathrm{~mL}$ of collagenasefree DMEM were added to each tube and the seminiferous tubule mass was removed by filtration through doubled, $100-\mu \mathrm{m}$ nylon mesh. The filtrates were centrifuged at $325 \mathrm{~g}$ for $3 \mathrm{~min}$ at room temperature. The supernatants were discarded. The residues were re-suspended in $5 \mathrm{~mL}$ PBS. The procedure of sedimentation was repeated.

The interstitial cell suspension was incubated with monoclonal antibodies specific to CD11b, CD8 alpha, CD25 (IL2 receptor alpha), $\mathrm{CD} 3$ conjugated to FITC and CD45, CD4 conjugated to PE (Abcam, UK). $5 \mu \mathrm{L}$ of antibody dilutions were added to $300 \mu \mathrm{L}$ of cell suspension. The cells were stained for 30 minutes. Then, the cells in the sample were washed with PBS and analyzed. The immunophenotyping of the testicular cells was done using FACS Calibour flow cytometer (Becton Dickinson, USA).

The testes were fixed, dehydrated in graded ethanol, cleared in xylene and embedded in paraffin wax. The sections were cut at 5 micrometers, stained with hematoxylin and eosin and observed under a light microscope (MEIJU Techno, Japan).

All data were processed by Statistica 6.0 package for Windows (Tulsa, OK, USA), and the results were expressed as median with 25th and 75th interquartile range. The statistical differences between groups' percentage points were determined using nonparametric KruskalWallis test. Multiple comparisons were tested using Mann-Whitney Utest with Bonferroni correction. The differences were considered reliable at $\mathrm{P}<0.05$.

\section{Results}

Flow Cytometry Analysis. Cd pretreatment did not have a reliable effect on the proportion of $\mathrm{CD} 45+, \mathrm{CD} 3+$ cells by week 4 in $\mathrm{Cd}$ group (Table 1) but the proportion of CD45+ then rose considerably by week 8 . The proportion of CD11b+ was lowered and it tended to decrease over the whole period of observation compared to I group. CD3+, CD8+, $\mathrm{CD} 4+$ cell proportions were lower than in I group but gradually increased to their normal range by week 8 . However, the lowest quantities of these cells were observed by week 12 . Moreover the heightened level of $\mathrm{CD} 4+\mathrm{CD} 25+$ subpopulation was pronounced in $\mathrm{Cd}$ group in relation to I group by week 4 but the level markedly decreased to the minimum at the later follow-up. In essence, these cells were not detected by 
weeks 8 and 12. Intratesticular transplantation alone caused a noticeable increase in CD11b+ content (Table 1) in ITT group over the whole-time frame of observation. CD45+, CD3+ and CD8+ contents stayed relatively stable by week 2 after transplantation but then demonstrated a sharp rise by week 4 especially in case of CD45+ and CD3+. Intratesticular transplantation resulted in a reliable increase in CD4+ and CD4+CD25+ cell subpopulation by weeks 4 and 8 . The proportions of all studied cells got back to the normal level by week 8 after transplantation.

Combined effect of transplantation and $\mathrm{Cd}$ pretreatment elevated the proportions of all cell populations (Table 1). The increase to the levels of $\mathrm{CD} 45+, \mathrm{CD} 3+, \mathrm{CD} 8+, \mathrm{CD} 4+$ was very pronounced by weeks
2 and 4 compared to $\mathrm{Cd}$ and ITT groups. Then the proportions of the cells gradually decrease by week 8 after transplantation.

Histological examination. In $\mathrm{Cd}$ and $\mathrm{Cd}^{+}$ITT groups, $\mathrm{Cd}$ injection resulted in a severe inflammation by the next day. The peritubular capillaries of the testes were engorged with blood. Intratubular edema was present (data were not shown). The germinal epithelium was sloughed. This acute inflammatory process, however, weakened by the fourth week after $\mathrm{Cd}$ administration. However, the foci of cellular detritus remained in places of seminiferous tubules and development of fibrous tissue was detected in between the seminiferous tubules. The $\mathrm{Cd}^{+}$ITT group was subject to transplantation after four weeks of such a $\mathrm{Cd}$ injection.

Table 1

The proportion of immune cells of testicular interstitial tissue Median and 25th-75th percentile

\begin{tabular}{|c|c|c|c|c|c|c|c|}
\hline Groups & Subpopulations: & $\mathrm{CD}_{11 b^{+}}$ & $\mathrm{CD}_{4} 5^{+}$ & $\mathrm{CD}^{+}$ & $\mathrm{CD}^{+}$ & $\mathrm{CD}^{+}$ & $\mathrm{CD}^{+} \mathrm{CD} 25^{+}$ \\
\hline \multirow[b]{2}{*}{ I group } & \multirow{2}{*}{ Standard values } & 7.48 & 2.75 & 2.05 & 0.76 & 0.75 & 0.02 \\
\hline & & $6.61-8.45$ & $2.35-2.99$ & $1.79-2.24$ & $0.69-0.83$ & $0.65-0.89$ & $0.01-0.04$ \\
\hline \multirow{8}{*}{ Cd group } & \multirow{2}{*}{4 week after injection } & $2.29^{*}$ & 2.24 & 1.51 & $0.21^{*}$ & $0.30^{*}$ & $0.11^{*}$ \\
\hline & & $2.01-2.58$ & $1.97-2.56$ & $1.35-1.69$ & $0.18-0.23$ & $0.25-0.36$ & $0.07-0.12$ \\
\hline & \multirow{2}{*}{6 week after $\mathrm{Cd}$ injection } & $1.04^{*}$ & 3.58 & 1.75 & 0.46 & 0.45 & 0.01 \\
\hline & & $0.89-1.15$ & $3.25-4.14$ & $1.49-2.05$ & $0.41-0.49$ & $0.38-0.52$ & $0.00-0.01$ \\
\hline & \multirow{2}{*}{8 week after Cd injection } & $0.51^{*}$ & $4.41^{*}$ & 2.02 & 0.75 & 0.76 & 0.00 \\
\hline & & $0.13-0.17$ & $5.12-3.91$ & $1.83-2.35$ & $0.68-0.82$ & $0.68-0.81$ & $0.00-0.01$ \\
\hline & \multirow{2}{*}{12 week after Cd injection } & $0.15^{*}$ & 1.49 & $0.81^{*}$ & $0.21^{*}$ & $0.21^{*}$ & 0.00 \\
\hline & & $0.13-0.17$ & $1.35-1.74$ & $0.73-0.88$ & $0.19-0.23$ & $0.18-0.23$ & $0.00-0.00$ \\
\hline \multirow{6}{*}{ ITT group } & \multirow{2}{*}{ Week 2} & $12.34^{*}$ & 3.21 & 2.55 & 0.78 & $1.27^{*}$ & $0.10^{*}$ \\
\hline & & $6.61-8.45$ & $2.82-3.67$ & $2.23-2.83$ & $0.69-0.93$ & $1.16-1.42$ & $0.08-0.13$ \\
\hline & \multirow{2}{*}{ Week 4} & $10.97^{*}$ & $8.06^{*}$ & $6.18^{*}$ & $1.05^{*}$ & $1.52^{*}$ & 0.04 \\
\hline & & $10.12-12.6$ & $7.12-9.12$ & $5.34-6.74$ & $0.82-1.13$ & $1.28-1.74$ & $0.03-0.05$ \\
\hline & \multirow{2}{*}{ Week 8} & 10.72 & 4.24 & 2.00 & 1.44 & 1.03 & 0.05 \\
\hline & & $9.31-12.37$ & $3.72-4.71$ & $1.83-2.47$ & $1.39-1.73$ & $0.89-1.15$ & $0.03-0.05$ \\
\hline \multirow{6}{*}{$\begin{array}{l}\mathrm{Cd}^{+} \mathrm{ITT} \\
\text { group }\end{array}$} & \multirow{2}{*}{ Week 2 (6 week after Cd injection } & $13.31^{\#}$ & $34.28^{\#,+}$ & $32.59^{\#,+}$ & $18.73^{\#,+}$ & $8.91^{\#,+}$ & $0.20^{\#}$ \\
\hline & & $11.26-14.58$ & $30.37-38.37$ & $29.55-35.28$ & $16.72-20.16$ & $8.01-9.95$ & $0.16-0.23$ \\
\hline & \multirow{2}{*}{ Week 4 ( 8 week after Cd jnjection) } & $9.20^{\#}$ & $20.57^{\#,+}$ & $14.47^{\#,+}$ & $2.47^{\#,+}$ & $2.57^{\#,+}$ & $0.31^{\#,+}$ \\
\hline & & $8.13-10.21$ & $17.34-22.99$ & $13.24-16.32$ & $2.21-2.85$ & $2.10-2.92$ & $0.23-0.34$ \\
\hline & \multirow{2}{*}{ Week 8 (12 week after Cd injection) } & $7.10^{\#}$ & $12.16^{\#,+}$ & $4.91^{\#,+}$ & $2.00^{\#}$ & $1.53^{\#,+}$ & $0.09^{\#}$ \\
\hline & & $5.55-8.45$ & $11.08-13.57$ & $4.55-5.45$ & $1.79-2.31$ & $1.38-1.72$ & $0.06-0.13$ \\
\hline
\end{tabular}

Note: the statistical differences between groups' percentage points were determined using nonparametric Kruskal-Wallis test; multiple comparisons were tested using Mann-Whitney U-test with Bonferroni correction; the differences were considered reliable at $\mathrm{P}<0.05$; * $\mathrm{P}<0.05$, statistically significant with respect to I group; ${ }^{\#} \mathrm{P}<0.05$, statistically significant with respect to corresponding values of $\mathrm{Cd}$ group; ${ }^{+} \mathrm{P}<0.05$, statistically significant with respect to corresponding values of ITT group.

Histological examination of neonatal testis before the transplantation showed that it consisted of immature seminiferous tubules having the diameter of 20-30 $\mu \mathrm{m}$ (Fig. 2a). Spermatogonia were at the center of the tubule. Primitive Sertoli cell and singular gonocytes/prospermatogonia were located at the periphery of seminiferous tubules and close to the basal membrane. The lumen of seminiferous tubules was absent. Loose connective tissue was situated in between the seminiferous tubules. It occupied more than a half of the area of cross-sections.

After two weeks of transplantation the steady development of grafts was observed in ITT group (Fig. 2b). The Sertoli cells were lined along the basal region of the tubules. In the ITT group, spermatogonia were localized in the peripheral layer of seminiferous tubules. Interestingly, many seminiferous tubules of the ITT group had advanced populations of spermatogenic cells such as spermatocytes. The formation of luminal cavity was observed in several seminiferous tubules. Interstital tissue possessed some mature traits: they were tightly adjoined to one another.

The neonatal testis grafts in the Cd+ITT group were less advanced (Fig. 2c). The Sertoli cells were lined along the basal region of the tubules. Some spermatogonia were found on the basal membrane. The seminiferous tubules did not contain either spermatocytes nor other populations of germinal epithelium. The tubules were separated by a wide layer of connective tissue. Although foci of lymphoid infiltrate were not seen in the graft its development seemed to be depressed compared to the ITT group. Vacuoles and desquamated germinal epithelium were seen in almost all tubules of $\mathrm{Cd}^{+}$ITT group grafts by week 2 . The UKT group grafts had remnants of seminiferous tubules by week 2 (Fig. 2d). The lumen of their seminiferous tubules contained nothing. There was cellular detritus in the centers of some seminiferous tubules. Few Sertoli cells were observed on the periphery. Interstitial tissue was degraded. The seminiferous tubules of the ITT group comprised normally shaped Sertoli cells four weeks after transplantation (Fig. 3a). The single spermatogonia were seen in between the Sertoli cells and basement membrane. In the center of seminiferous tubules, desquamated germinal epithelium was present.

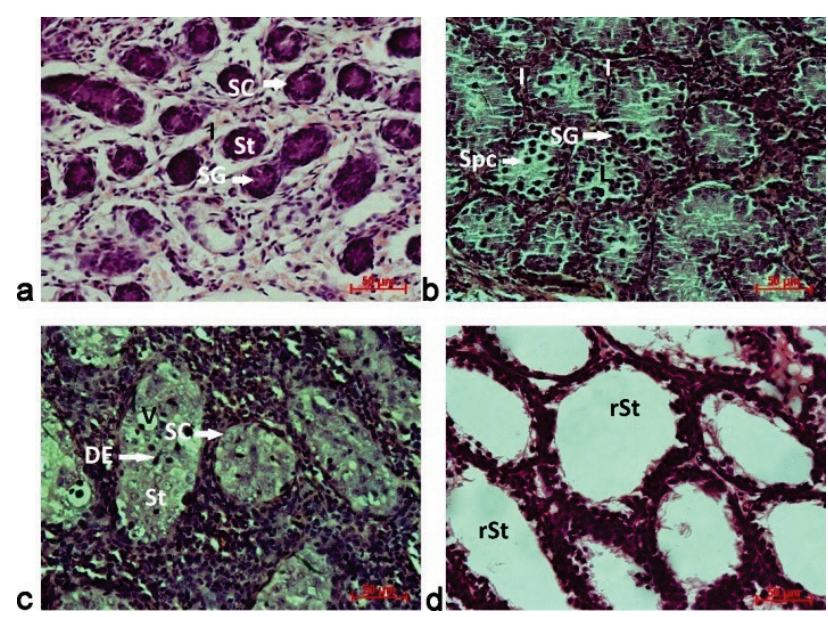

Fig. 2. The histological structure of neonatal murine testes before and after two weeks of transplantation: $a$ - neonatal murine testis; $b-$ I group graft by week 2 after transplantation; $c-\mathrm{Cd}+\mathrm{IT}$ group graft by week 2 after transplantation (week 6 after Cd administration); $d$ - UKT group graft by week 2 after transplantation:

$\mathrm{St}$ - seminiferous tubules; I - interstitial tissue; SC - Sertoli cells; $\mathrm{SG}$ - spermatogonia; Spc - spermatocytes; $\mathrm{L}$ - lumen of seminiferous tubules; $\mathrm{rSt}$ - remnants of seminiferous tubules; $\mathrm{V}$ - vacuoles; DE - desquamated epithelium 

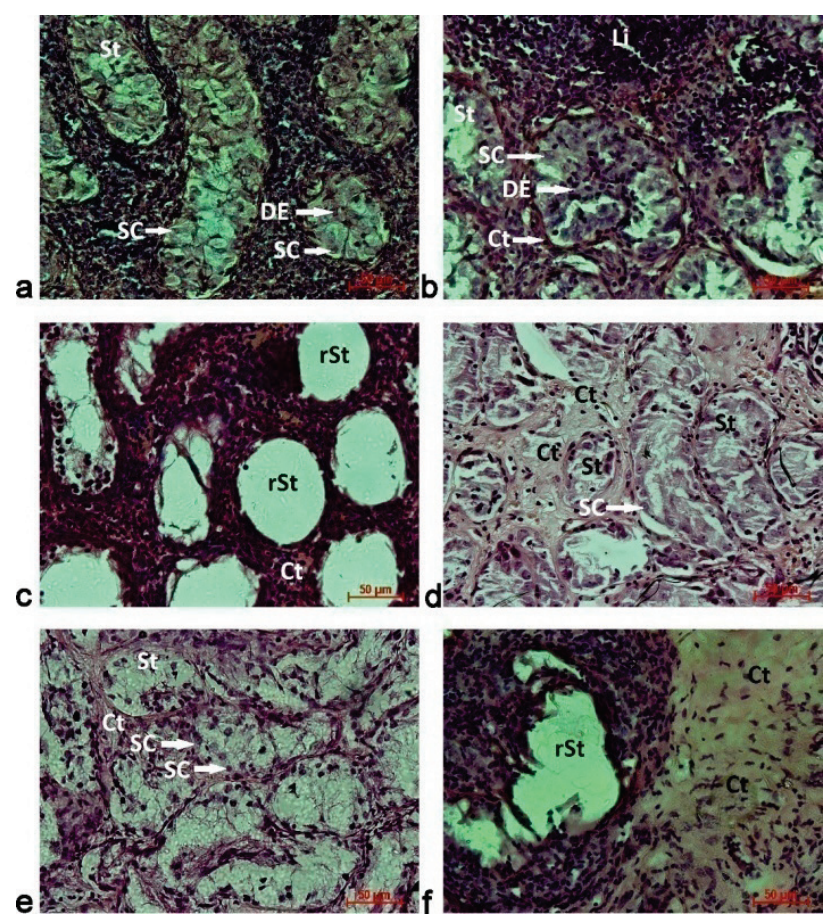

Fig. 3. The histological structure of neonatal murine testes after four and eight weeks of transplantation: $a$ - I group graft by week 4 after transplantation; $b-\mathrm{Cd}^{+}$IT group graft by week 4 after transplantation (week 8 after Cd administration); $c$ - UKT group graft by week 4 after transplantation; $d$ - I group graft by week 8 after transplantation; $e-\mathrm{Cd}+\mathrm{IT}$ group graft by week 8 after transplantation (week 12 after Cd administration); $f$ - UKT group graft by week 8 after transplantation; $\mathrm{St}$ - seminiferous tubules; I - interstitial tissue;

$\mathrm{SC}$ - Sertoli cells; SG - spermatogonia; Spc - spermatocytes;

$\mathrm{L}$ - lumen of seminiferous tubules; $\mathrm{rSt}$ - remnants of seminiferous tubules; V - vacuole; DE - desquamated epithelium; $\mathrm{Ct}$ - connective tissue

The interstitial tissue of ITT grafts was thickened. There was also leukocyte infiltration in this interstitial tissue.

As for $\mathrm{Cd}^{+}$ITT group grafts by week 4, their histological appearance showed irregularly shaped Sertoli cells that were lining the seminiferous tubules (Fig. 3b). Detachment of the germinal epithelium from the wall of the seminiferous tubule was observed. The detritus of germinal epithelium was seen in the center of some tubules. Foci of lymphoid infiltration and connective tissue development were shown in between the seminiferous tubules. Dense fibrous capsules formed around the seminiferous tubules. There were no seminiferous tubules in the UKT group grafts by week 4 . These grafts had cystic-like cavities in places of seminiferous tubules (Fig. 3c). The boundaries between the remnants of the seminiferous tubules and interstitial tissue were blurred. The fibrous tissue formed in the grafts.

By week 8, there was no apparent difference in the architecture between seminiferous tubules of the ITT and Cd+ITT group grafts (Fig. 3d, e). These grafts were primarily represented by Sertoli cell-only tubules. The formation of connective tissue took place in between the seminiferous tubules. As for the UKT group by week 8, there was a total replacement of graft by connective tissue (Fig. 3f).

\section{Discussion}

$\mathrm{CD} 11 \mathrm{~b}$ is implicated in various adhesive interactions of monocytes, macrophages and granulocytes as well as in mediating the uptake of complement coated particles. CD11b is also a receptor for fibrinogen, factor X, and ICAM1 (Fendl et al., 2018). CD45 is a family of single chain transmembraneous glycoproteins. It is expressed on cells of the human hematopoietic lineage with the exception of mature red blood cells. It is not detected on differentiated cells of other tissues. CD45 plays an important role in signal transduction, inhibition or upregulation of various immunological reactions (Rheinländer et al., 2018). Of note, macrophages present in the testicular interstitial tissue do not normally express CD45 (Mullen et al., 2003). CD3 is a component of T-cell receptor. The antigen is present on most peripheral blood lymphocytes, $65-85 \%$ of thymocytes (De Rose et al., 2013). It plays a role in T-cell receptor-induced growth arrest, cell survival and proliferation. The CD8 antigen is a cell surface glycoprotein found on most cytotoxic T lymphocytes that mediates efficient cell to cell interactions within the immune system (Diao \& Pipkin, 2019). The CD8 antigen, acting as a coreceptor, and the $\mathrm{T}$ cell receptor on the $\mathrm{T}$ lymphocyte recognize antigen displayed by an antigen presenting cell in the context of class I MHC molecules. CD4 is a single chain transmembraneous glycoprotein which belongs to the immunoglobulin superfamily. CD4 is present on a subset of T lymphocytes ("helper/inducer" $T$ cells) and is also expressed at lower level on monocytes, tissue macrophages and granulocytes. The antigen is involved in binding to MHC class II molecules (Sweet et al., 1991). Its intracellular domain is associated with a type of protein tyrosine kinase. CD25 is a part of IL2 receptor present on activated T and B cells, thymocyte subset, pre B cells and T regulatory cells (Vaikunthanathan et al., 2017). Thus, the markers reflect the development of local inflammatory process and cellular response of recipient on foreign tissue grafting.

Acute short-term Cd effect on testicular tissue was thoroughly described by Pak (1988), Marettová et al. (2010) and Abarikwu et al. (2019). Our findings corroborate the data: the testes were inflamed immediately after Cd injection. There were multiple hemorrhages observed in testicular parenchyma. Seminiferous epithelium was severely damaged.

However, the acute inflammatory process ended by the fourth week after Cd administration because the levels of potentially pro-inflammatory cells (CD11b+, CD3+, CD8+) were even lower than in the I group. Taking these into account, the fourth week after $\mathrm{Cd}$ injection (the time point which was characterized by the dampened inflammatory response on Cd injection) was chosen as a suitable moment for intratesticular transplantation and for investigation of long-term effects of $\mathrm{Cd}$. In this case the development of graft tissue can reflect the changes in testicular immunology, hormone production and other functions. Another consequence of the inflammation was the total irreversible damage of host germinal epithelium by week 4 after injection. One other consequence may include specific $\mathrm{Cd}$ effects well documented in the literature such as the disruption of tight and gap junction playing a role in maintaining the BTB (Cheng et al., 2011; Zhang \& Lui, 2014; RamosTreviño et al., 2017). It is not clear to what extent the latter changes are reversible. It is also not well understood how the absence of germinal epithelium may affect testis immunity and other function such as hormone production on a long-term scale after Cd exposure.

The investigation of under-the-kidney capsule versus intratesticular grafts helped establish the fact of immune tolerance. The comparison of the types of transplantations showed that intratesticular transplantation promoted graft survival in both the ITT and $\mathrm{Cd}^{+}$ITT groups. Intratesticularly transplanted grafts represented steady development during the first two week after transplantation. Advanced germ cell populations were seen in the ITT and $\mathrm{Cd}^{+}$ITT groups but not in the UKT group. The UKT group grafts were degrading and being replaced by connective tissue.

Testicular macrophages are the most abundant immune cells residing in the testis, an immune-privileged organ. They exhibit different functions, such as protecting spermatozoa from auto-immune attack by producing immunosuppressive cytokines and trophic roles in supporting spermatogenesis and male sex hormone production. Testicular macrophages share common core tissue-resident macrophage markers as F4/80, CD11b, CD64, M-CSFR (Gordon, 2002; Gautier et al., 2012; Gentek et al., 2014; Mossadegh-Keller \&Sieweke, 2019). One characteristic of cellular response on the intratesticular transplantation of newborn testes was an increase in the CD11b+ cell content. However, they are characterized by a subdued proinflammatory response, a polarization toward the immunoregulatory and immunotolerant phenotype that enables them to play a relevant role in the functions of the testis. During infection, the characteristic blunted immune response of tissue macro- 
phages reflects the need for a delicate balance between a sufficiently strong reaction to counteract invading pathogens, and the prevention of excessive proinflammatory cytokine levels with the potential to disturb or destroy spermatogenesis (Meinhardt et al., 2018). The content of $\mathrm{CD} 11 \mathrm{~b}+$ cells remained elevated over a period of observation.

Another characteristic of intratesticular transplantation can be outlined in the following way: groups with intratesticular grafts (ITT and $\mathrm{Cd}^{+}$ITT) responded to transplantation by an increase in the subpopulation of CD4+ CD25+ cells. Regulatory T cells (Tregs) having a phenotype CD4+ CD25+ mediate tolerance to self-antigens maintaining immune homeostasis (Nasr et al., 2005). Defects in the number and function of $\mathrm{T}_{\text {reg }}$ lead to aberrant immune responses to autologous components, thereby causing autoimmune diseases and male infertility (Jacobo, 2018). However, Cd pretreatment resulted in a change in the balance between the CD4+ CD25+ and other cell subpopulations such as CD8+ and CD45+ after intratesticular transplantation. Although both groups with intratesticular transplantation possessed an elevated proportion of Tregs, the heightened level of proinflammatory CD45+ leukocytes and $\mathrm{CD} 8+\mathrm{T}$ lymphocytes in the $\mathrm{Cd}^{+}$ITT group apparently outnumbered Tregs or affected their immunosuppressive properties. Similar effects were described by Jacobo (2018).

Interestingly the obtained data are corroborated with histological appearance of intratesticular grafts. For example, in the $\mathrm{Cd}^{+}$ITT group grafts showed less advanced germ cell types (spermatogonia) than in Ithe TT group. They also had sloughed germinal epithelium and vacuoles by week 2 . By week 4 , however, in the $\mathrm{Cd}^{+}$ITT group the proportion of $\mathrm{T}_{\text {reg }}$ cells increased with respect to leukocytes and lymphocytes which to some extent suppressed the process of graft rejection. Therefore, intratesticular transplantation showed that $\mathrm{Cd}$ pretreatment resulted in a change in the balance of $\mathrm{T}_{\text {reg }}$ and other cell populations. This change manifested over a long period after $\mathrm{Cd}$ administration and transplantation (up to week 8) and could be attributed to long-term $\mathrm{Cd}$ effects on the testis.

As mentioned above, $\mathrm{Cd}$ administration disrupted host seminiferous epithelium but there is a considerable body of evidence that the element may influence interstitial compartments, such as Leydig, vascular, immune, and peritubular cells. The testis is especially susceptible to $\mathrm{Cd}$ exposure, which may decrease total and free testosterone levels resulting in hypogonadism (Chen et al., 2016; de Angelis et al., 2017). There are also models of $\mathrm{Cd}$ induced hypogonadism described (Potikha et al., 1993). Interstitial cells take part in complex signaling interactions with both interstitial and tubular cell populations, which are required for several biological processes, such as steroidogenesis, Sertoli cell function, spermatogenesis, and immune regulation (Heinrich \& DeFalco, 2019). However, it is questionable whether $\mathrm{Cd}$ injection resulted in low testosterone level after six weeks. It has been shown that regardless of $\mathrm{Cd}$ pretreatment, intratesticular graft spermatogonial cells proliferated, which indirectly testified adequate local hormonal level. Additionally, steady recovery of steroidogenic function and sexual behavior after acute Cd administration was shown (Pakhomov, 2013). Thus, Cd pretreatment could affect testis immunity even after several weeks of injection, which exacerbated inflammatory process in $\mathrm{ITT}^{+} \mathrm{Cd}$ group by week 4 after transplantation (week 8 after $\mathrm{Cd}$ administration).

It appears that immune privilege in the testis is maintained by unique testicular environment that controls immune cell activity and suppresses adaptive immunity in a tissue-localized manner (Raburn et al., 1993; Duckett et al., 1997). The process is active. It recruits many cell types and endo-/paracrine factors such as androgens produced by Leydig cells and TGF- $\beta$ (Kaur et al., 2013; Zhao et al., 2014). They are prerequisites for maintaining immune privilege status and spermatogenesis and we can speculate that these regulatory factors were also affected by $\mathrm{Cd}$ in $\mathrm{Cd}^{+}$ITT group.

Future studies of long-term effects of $\mathrm{Cd}$ should investigate in detail the role of other candidates for immune suppressive cells and humoral regulatory factors that promote immune privilege and maintain testicular homoeostasis. For example, CD8+ CD122+ T regulatory cells or TGF- $\beta$, IL- 4 , IL- 10 cytokines. There are also many agents that prevent or alleviate Cd intoxication (Kojima et al., 1992; Wahba et al., 1993; Alkhedaide et al., 2016; Abarikwu et al., 2019; Badr et al., 2019).
Therefore, it is of interest to investigate their impact on testis immunology on a long-term scale in combination with Cd impact. It may help to develop novel treatment approaches for acute and chronic $\mathrm{Cd}$ intoxication and for male fertility preservation in the future.

\section{Conclusion}

Cd pretreatment affected the balance between Treg cells and leukocytes/T-lymphocytes. This was demonstrated with flow cytometry analysis under intratesticular transplantation. The balance was important for the intratesticular graft development by the second week, which was proved by comparing outcomes of intratesticular transplantations of groups with and without $\mathrm{Cd}$ pretreatment. Although the disproportion of cell population affected immune privilege properties, the Cd pretreated testes were still able to foster graft survival when the non-immune privileged under-the-kidney capsule was not able to do so. It proves that acute Cd intoxication may have a long-term effect on the organism's health and male fertility.

\section{References}

Abarikwu, S. O., Wokoma, A. F. S., Mgbudom-Okah, C. J., Omeodu, S. I., \& Ohanador, R. (2018). Effect of Fe and Cd co-exposure on testicular steroid metabolism, morphometry, and spermatogenesis in mice. Biological Trace Element Research, 190(1), 109-123.

Alkhedaide, A., Alshehri, Z. S., Sabry, A., Abdel-Ghaffar, T., Soliman, M. M., \& Attia, H. (2016). Protective effect of grape seed extract against cadmium-induced testicular dysfunction. Molecular Medicine Reports, 13(4), 3101-3109.

Aoshima, K. (2017). Itai-itai disease: Lessons from the investigations of environmental epidemiology conducted in the 1970's, with special reference to the studies of the Toyama Institute of Health. Nippon Eiseigaku Zasshi (Japanese Journal of Hygiene), 72(3), 149-158.

Badr, G. M., Elsawy, H., Sedky, A., Eid, R., Ali, A., Abdallah, B. M., AbdelMoneim, A. M. (2019). Protective effects of quercetin supplementation against short-term toxicity of cadmium-induced hematological impairment, hypothyroidism, and testicular disturbances in albino rats. Environmental Science and Pollution Research, 26(8), 8202-8211.

Chakraborty, S., Gang, S., \& Sengupta, M. (2014). Functional status of testicular macrophages in an immunopriviledged niche in cadmium intoxicated murine testes. American Journal of Reproductive Immunology, 72(1), 14-21.

Chen, C., Wang, N., Nie, X., Han, B., Li, Q., Chen, Y., Zhai, H., Zhu, C., Chen, Y., Xia, F., Lu, M., Lin, D., \& Lu, Y. (2015). Blood cadmium level associates with lower testosterone and sex hormone-binding globulin in chinese men: From SPECT-China study, 2014. Biological Trace Element Research, 171(1), 71-78.

Chen, H., Lui, W., Mruk, D. D., Xiao, X., Ge, R., Lian, Q., \& Cheng, C. Y. (2018). Monitoring the integrity of the blood-testis barrier (BTB): An in vivo assay. Sertoli Cells, 245-252.

Chen, Q., Deng, T., \& Han, D. (2016). Testicular immunoregulation and spermatogenesis. Seminars in Cell and Developmental Biology, 59, 157-165.

Cheng, C. Y., Wong, E. W. P., Lie, P. P. Y., Li, M. W. M., Su, L., Siu, E. R., \& Mruk, D. D. (2011). Environmental toxicants and male reproductive function. Spermatogenesis, 1(1), 2-13.

De Angelis, C., Galdiero, M., Pivonello, C., Salzano, C., Gianfrilli, D., Piscitelli, P., \& Pivonello, R. (2017). The environment and male reproduction: The effect of cadmium exposure on reproductive function and its implication in fertility. Reproductive Toxicology, 73, 105-127.

De Rose, R., Fernandez, C. S., Hedger, M. P., Kent, S. J., \& Winnall, W. R. (2013) Characterisation of macaque testicular leucocyte populations and T-lymphocyte immunity. Journal of Reproductive Immunology, 100(2), 146-156.

Diao, H., \& Pipkin, M. (2019). Stability and flexibility in chromatin structure and transcription underlies memory CD8 T-cell differentiation. F1000Research, 8, 1278.

Duckett, R. J., Wreford, N. G., Meachem, S. J., McLachlan, R. I., \& Hedger, M. P. (1997). Effect of chorionic gonadotropin and flutamide on Leydig cell and macrophage populations in the testosterone-estradiol-implanted adult rat. Journal of Andrology, 18(6), 656-662.

Fendl, B., Eichhorn, T., Weiss, R., Tripisciano, C., Spittler, A., Fischer, M. B., \& Weber, V. (2018). Differential interaction of platelet-derived extracellular vesicles with circulating immune cells: Roles of TAM receptors, CD11b, and phosphatidylserine. Frontiers in Immunology, 2018, 9.

Gentek, R., Molawi, K., \& Sieweke, M. H. (2014). Tissue macrophage identity and self-renewal. Immunological Reviews, 262(1), 56-73.

Gordon, S. (2002). Pattern recognition receptors. Cell, 111(7), 927-930.

Halder, S., Kar, R., Chakraborty, S., Bhattacharya, S. K., Mediratta, P. K., \& Banerjee, B. D. (2019). Cadmium level in brain correlates with memory im- 
pairment in F1 and F2 generation mice: Improvement with quercetin. Environmental Science and Pollution Research, 26(10), 9632-9639.

Heinrich, A., \& DeFalco, T. (2019). Essential roles of interstitial cells in testicular development and function. Andrology, 2019, 1-12.

Hu, X., Fernandes, J., Jones, D. P., \& Go, Y.-M. (2017). Cadmium stimulates myofibroblast differentiation and mouse lung fibrosis. Toxicology, 383, 50-56.

Hutka, M., Smith, L. B., \& Mitchell, R. T. (2017). Xenotransplantation as a model for human testicular development. Differentiation, 97, 44-53.

Jacobo, P. (2018). The role of regulatory T cells in autoimmune orchitis. Andrologia, 50(11), e13092.

Kaur, G., Mital, P., \& Dufour, J. M. (2013). Testis immune privilege - Assumptions versus facts. Animal Reproduction, 10(1), 3-15.

Kojima, S., Sugimura, Y., Hirukawa, H., Kiyozumi, M., Shimada, H., \& Funakoshi, T. (1992). Effects of dithiocarbamates on testicular toxicity in rats caused by acute exposure to cadmium. Toxicology and Applied Pharmacology, 116(1), 24-29.

Marettová, E., Maretta, M., \& Legáth, J. (2009). Changes in the peritubular tissue of rat testis after cadmium treatment. Biological Trace Element Research, 134(3), 288-295.

McCracken, K., \& Nahata, L. (2017). Fertility preservation in children and adolescents. Current Opinion in Obstetrics and Gynecology, 29(5), 283-288.

Meinhardt, A., Wang, M., Schulz, C., \& Bhushan, S. (2018). Microenvironmental signals govern the cellular identity of testicular macrophages. Journal of Leukocyte Biology, 104(4), 757-766.

Mossadegh-Keller, N., \& Sieweke, M. (2019). Characterization of mouse adult testicular macrophage populations by immunofluorescence imaging and flow cytometry. Bio-Protocol, 9, 5 .

Mossadegh-Keller, N., \& Sieweke, M. H. (2018). Testicular macrophages: Guardians of fertility. Cellular Immunology, 330, 120-125.

Mouro, V. G. S., de Melo, F. C. S. A., Martins, A. L. P., de Lucca Moreir Gomes, M., de Oliveira, J. M., de Freitas, M. B. D., Demuner, A. J., Leite, J. P. V., \& da Matta, S. L. P. (2020). Euterpe oleracea (Martius) oil reverses testicular alterations caused after cadmium administration. Biological Trace Element Research, 2020, in print.

Mullen, T. E., Kiessling, R. L., \& Kiessling, A. A. (2003). Tissue-specific populations of leukocytes in semen-producing organs of the normal, hemicastrated, and vasectomized mouse. AIDS Research and Human Retroviruses, 19(3), 235-243.

Nasr, I. W., Wang, Y., Gao, G., Deng, S., Diggs, L., Rothstein, D. M., Tellides, G., Lakkis, F. G., \& Dai, Z. (2005). Testicular immune privilege promotes transplantation tolerance by altering the balance between memory and regulatory T cells. The Journal of Immunology, 174(10), 6161-6168.

Pak, R. C. K. (1988). Effects of a testicotoxic dose of cadmium on the liver and drug metabolism in the rat. Comparative Biochemistry and Physiology Part C: Comparative Pharmacology, 89(2), 305-309.

Pakhomov, O. (2013). Correction of reproductive behavior malfunctions of male rats with experimental hypogonadism affected by cadmium chloride intoxication by means of hormonotherapy and transplantation of interstitial cell suspension. Journal of V. N. Karazin National University, Series "Biology", $17,171-177$.
Raburn, D. J., Coquelin, A., Reinhart, A. J., \& Hutson, J. C. (1993). Regulation of the macrophage population in postnatal rat testis. Journal of Reproductive Immunology, 24(2), 139-151.

Ramos-Treviño, J., Bassol-Mayagoitia, S., Hernández-Ibarra, J. A., Ruiz-Flores, P., \& Nava-Hernández, M. P. (2018). Toxic effect of cadmium, lead, and arsenic on the sertoli cell: Mechanisms of damage involved. DNA and Cell Biology, 37(7), 600-608.

Ramos-Treviño, J., Bassol-Mayagoitia, S., Ruiz-Flores, P., Espino-Silva, P. K., Saucedo-Cárdenas, O., Villa-Cedillo, S. A., \& Nava-Hernández, M. P. (2017). In vitro evaluation of damage by heavy metals in tight and gap junctions of sertoli cells. DNA and Cell Biology, 36(10), 829-836.

Rheinländer, A., Schraven, B., \& Bommhardt, U. (2018). CD45 in human physiology and clinical medicine. Immunology Letters, 196, 22-32.

Rinaldi, M., Micali, A., Marini, H., Adamo, E. B., Puzzolo, D., Pisani, A., Trichilo, V., Altavilla, D., Squadrito, F., \& Minutoli, L. (2017). Cadmium, organ toxicity and therapeutic approaches: A review on brain, kidney and testis damage. Current Medicinal Chemistry, 24, 35.

Salama, S. A., Arab, H. H., Hassan, M. H., Al Robaian Majed, M., \& Maghrabi, I. A (2019). Cadmium-induced hepatocellular injury: Modulatory effects of $\gamma$-glutamyl cysteine on the biomarkers of inflammation, DNA damage, and apoptotic cell death. Journal of Trace Elements in Medicine and Biology, 52, 74-82.

Samuel-Nakamura, C., Hodge, F. S., Sokolow, S., Ali, A.-M. S., \& Robbins, W. A (2019). Metal(loid)s in Cucurbita pepo in a uranium mining impacted area in Northwestern New Mexico, USA. International Joumal of Environmental Research and Public Health, 16(14), 2569

Schlatt, S., Honaramooz, A., Boiani M., Schöler H. R., \& Dobrinski, I. (2003). Progeny from sperm obtained after ectopic grafting of neonatal mouse testes. Biology of Reproduction, 68(6), 2331-2335.

Shaw, J. M. \& Trounson, A. O. (2002). Ovarian tissue transplantation and cryopreservation: Application to maintenance and recovery of transgenic and inbred mouse lines. Methods in Molecular Biology, 180, 229-251.

Sweet, R. W., Truneh, A., \& Hendrickson, W. A. (1991). CD4: Its structure, role in immune function and AIDS pathogenesis, and potential as a pharmacological target. Current Opinion in Biotechnology, 2(4), 622-633.

Vaikunthanathan, T., Safinia, N., Boardman, D., Lechler, R. I., \& Lombardi, G. (2017). Regulatory T cells: Tolerance induction in solid organ transplantation. Clinical and Experimental Immunology, 189(2), 197-210.

Wahba, Z. Z., Coogan, T. P., Rhodes, S. W., \& Waalkes, M. P. (1993). Protective effects of selenium on cadmium toxicity in rats: Role of altered toxicokinetics and metallothionein. Journal of Toxicology and Environmental Health, $38(2), 171-182$.

Yang, H., \& Shu, Y. (2015). Cadmium transporters in the kidney and cadmium-induced nephrotoxicity. International Journal of Molecular Sciences, 16(1), 1484-1494.

Zhang, X., \& Lui, W.-Y. (2014). Dysregulation of nectin-2 in the testicular cells: An explanation of cadmium-induced male infertility. Biochimica et Biophysica Acta (BBA) - Gene Regulatory Mechanisms, 1839(9), 873-884.

Zhao, S., Zhu, W., Xue, S., \& Han, D. (2014). Testicular defense systems: Immune privilege and innate immunity. Cellular and Molecular Immunology, $11(5), 428-437$. 